\title{
Antioxidant Activities of Extracts of Endophytic Fungi Isolated from Healthy Leaves of Carica Papaya
}

\author{
U.M. Okezie $^{1^{*}}$, O. A. Okolia, E.E. Ajaegbu ${ }^{2}$, F.B.C. Okoye ${ }^{3}$, C.O. Esimone ${ }^{1}$ \\ ${ }^{1}$ Department of Pharmaceutical Microbiology and Biotechnology, Nnamdi Azikiwe, University, Awka, Nigeria \\ ${ }^{2}$ Department of Applied Sciences, Federal College of Dental Technology and Therapy, Enugu, Nigeria \\ ${ }^{3}$ Department of Pharmaceutical and Medicinal Chemistry, Nnamdi Azikiwe University, Awka, Nigeria
}

*Corresponding Author: U.M. Okezie, Department of Pharmaceutical Microbiology and Biotechnology, Nnamdi Azikiwe, University, Awka, Nigeria.

\begin{abstract}
The importance of the availability of good antioxidants for human health and the associated health challenges as a result of its deficiency calls for a search for newer bioactive compounds with the potentials to scavenge free radicals thus preventing oxidative stress. In this study, the antioxidant activities of some endophytic fungal extracts CP1, CP2, CP3, CP4, CP5, CP6 and CP7 were determined using DPPH radical scavenging assay and their respective percentage inhibition recorded. Also, the active constituents were detected using HPLC analysis. At a maximum concentration of $100 \mu \mathrm{g} / \mathrm{mL}$, The fungal extracts Cp1, Cp5, Cp2 and Cp7 produced 54.7\% $13.2,51.3 \% \pm 3.5,51.0 \% \pm 2.0$, and $50.0 \% \pm 3.6$ inhibition of free radicals; IC50 $85 \pm 1.5,97.5 \pm 3.5,98 \pm 2.0$ and $100 \pm 3.6$ respectively. These activities were observed to be moderate when compared to that of the standard ascorbic acid $75.0 \pm 2.6 \%$. Four bioactive compounds beauvericin, p-methoxycoumarin, indol-3-carbaldehyde and pavetannin A2 were detected in the crude extract (fermentation product) of endophytic fungi isolated in this work. Based on their chemical structure having multiple hydroxyl groups and other substitutes, these compounds are suggested as possible lead compounds for the development of antioxidant drugs.
\end{abstract}

Keywords: Antioxidant, Phenolic compounds, Carica papaya, Endophytic fungi

\section{INTRODUCTION}

Increased inflammation coupled with certain disorders and neurological diseases has been linked to oxidative stress. Several authors have confirmed this to be the result when reactive oxygen species attack biomolecules disrupting the balance between the formation and reduction of these reactive oxygen species (Xican et al., 2011; Igor et al., 2017). Administration of antioxidants is important in maintaining this balance and inhibiting the attack by these moieties (Marja P. Ka"hko"nen., 1999). Synthetic antioxidants used for this purpose have been reported to be toxic to the liver and this has triggered the search for a newer agent with good antioxidant capacities and at the same time not toxic (Xican et al., 2011).

Phenolic compounds such as phenolic acids, flavonoids, tannins have been observed to be the principal phytoconstituents produced by plants with good radical scavenging activities. They function by either preventing the formation of the free radicals or by inhibiting them before they can damage the cellular components (Igor et al., 2017).

Endophytic fungi which harbor internal tissues of plants have been shown to possess unprecedented chemodiversity and represent a reliable source of lead compounds needed for the development of antioxidant, antimicrobial, anti-inflammatory, anticancer agents, etc. (Vinton et al; 2001; Cannon, 2002; Filip et al; 2003; John et al., 2018; Okoye et al., 2015 \& 2013; Okezie et al., 2017 \& Okezie et al., 2015). Several phenolic compounds have been isolated from fermentation products of several endophytic fungi with high throughput-screening establishing various biological activities of these classes of compounds. Also, analysis ofthe effects of the structure (substituents) of phenolic compounds on radical scavenging activities reveals a positive correlation (Igor et al., 2017).

Carica papaya belongs to the family of Caricaceae commonly called pawpaw (English), Ibebe (Yoruba- Nigeria), or Okroegbe (Igbo-Nigeria). Several species of Caricaceae have been used as 
aremedy against a variety of infections (Alabi et al., 2012). C. papaya is a nutraceutical plant rich in vitamins and also having a wide range of pharmacological activities (Aravind et al., 2013).Bioactive (phenolic) compounds such as protocatechuic acid, p-coumaric acid and caffeic acid have been detected in its leaf extract (Canini et al., 2007). Recent data gathered from previous studies targeted at identifying and isolating bioactive antioxidant agents reveals endophytic fungi as a promising and reliable source of antioxidants due to their untapped chemodiversity (John et al., 2018). This study was therefore designed to investigate the antioxidant activity of endophytic fungal extracts isolated from healthy leaves of $C$. papaya and to determine the chemical constituents that may be present in the extracts. This formed the basis upon which this study was conducted.

\section{MATERIALS AND METHODS}

\subsection{Plant Material}

C papaya leaves were collected from farmland located in Nneogidi village in Agulu, Anambra State, Nigeria and were immediately transferred in a polythene bag. They were identified by a botanist Mrs. Emezie Anthonia of the Department of Pharmacognosy, Faculty of Pharmaceutical Sciences, Nnamdi Azikiwe University, Awka, Nigeria.

\subsection{Isolation and Purification of Endophytic Fungi}

All the harvested leaves were subjected to appropriate disinfection processes before culturing. The leaves were thoroughly washed in running tap water, followed by washing with sterile double distilled water to remove particles of dust. To eliminate epiphytic microorganisms, all the samples were further immersed in $70 \%$ ethanol and $2 \%$ sodium hypochlorite solution for 3 and 5 min respectively, before a final rinse in sterilized double-distilled water. The samples were dried in the laminar flow on a sterile filter paper (blotting). After the disinfection processes were carried out, a sterile knife blade was used to cut the samples to approximately $2 \mathrm{~cm}$ in length. Then the segments were inoculated into the previously sterilized agar fortified with chloramphenicol $500 \mathrm{mg} / \mathrm{L}$ using sterile forceps and applying the minimum amount of pressure. The Petri dishes were properly sealed using parafilm, then incubated at $25^{\circ} \mathrm{C}$ in the incubator for 5-7 days, while observations for the emergence of hypha were done on alternate days. During the incubation period, emerged hyphal tips of actively growing fungi from the plant material inoculated were then isolated and transferred to fresh sterile MEA plate (purification) and were incubated appropriately (Okezie et al., 2017). Seven pure isolates were subjected to fermentation.

\subsection{Fermentation of Pure Isolates}

Local rice served as the fermentation medium. Here, $100 \mathrm{~g}$ of the local rice was weighed into a sterile conical flask and $200 \mathrm{~mL}$ of sterile water added and sterilized appropriately at $121^{\circ} \mathrm{C}$ for 30 mins. After sterilization, the mediums were then allowed to cool properly. The segments were aseptically cut using a sterile spatula from the actively growing pure isolates on MEA and transferred into the fermentation medium contained in a 1000-mL Erlenmeyer flask, this was properly sealed and kept on the shelf for a maximum of 21 days at $30^{\circ} \mathrm{C}$ under static conditions (Okezie et al., 2017).The fermentation was done on a small scale i.e. one fermentation medium per fungus.

\subsection{Extraction of Fungal Metabolites}

The fermentation products were recovered by the addition of $500 \mathrm{~mL}$ ethyl acetate into each of the fermentation cultures, followed by homogenization using a sterile glass rod. The flask was agitated at an interval of $1 \mathrm{hr}$ for 2 days and then filtered using Whatman filter paper (size: $188 \mathrm{~mm}$ ). The filtrates were concentrated at $50^{\circ} \mathrm{C}$ under reduced pressure using a rotary evaporator. The concentrated extract was further left to evaporate to dryness in a desiccator containing sodium hydroxide (Okezie $e t$ al., 2017).

After evaporation, the corresponding extracts were weighed and their respective percentage yieldswere recorded in milligram. In other to test for biological activities, the dried fungal extracts were reconstituted in dimethyl sulphoxide (DMSO).

\subsection{Analytical HPLC of the Extracts}

This was carried out according to the methods of Ajaegbu et al., 2016 \& Ajaegbu et al., 2020. This was carried out with a Dionex P580 HPLC system coupled to a photodiode array detector (UVD340S, 
Dionex Softron GmbH, Germering, Germany) at different lambda max (235, 254, 280 and $340 \mathrm{~nm})$. Each sample (fraction) was dissolved using $2 \mathrm{ml}$ of HPLC grade methanol, and $100 \mu \mathrm{l}$ of the dissolved samples were each transferred into the vials of HPLC. The separation column

(125 x $0.4 \mathrm{~cm}$; length x internal diameter) was prefilled with Eurospher-10 C18 (Knauer, Germany), and a linear gradient of Nano pure water (adjusted to $\mathrm{pH} 2$ by addition of formic acid) using methanol as the eluent. The absorption peaks for the fractions were analyzed by comparing it with those in the HPLCUV/Visible library.

\subsection{Antioxidant Propertiesof the Extracts}

The free radical scavenging potentials of the endophytic fungal extracts were carried out as described by Chigozieet al., 2020, with some modifications. The free radical scavenging properties of the extracts against 2,2-diphenyl-1-picryl hydrazyl (DPPH) radical were measured at $490 \mathrm{~nm}$. The concentrations of the extracts and ascorbic acid used were $20,40,60,80$, and $100 \mu \mathrm{g} / \mathrm{mL}$ The reaction mixture consists of $25 \mu \mathrm{l}$ of the stock, $25 \mu \mathrm{l}$ of DPPH $(0.1 \mathrm{~mol} / \mathrm{L})$ and $150 \mu \mathrm{l}$ of methanol solution. These were added into their respective wells in the microtiter. The plate was incubated at $27^{\circ} \mathrm{C}$ for 30 min.The absorbance of the mixtures was measured at $490 \mathrm{~nm}$ using a UV-vis spectrophotometer (06452; USA). The experiment was done in triplicate for each fungal extract.

Free radical scavenging activities were expressed as the percentage inhibition of each extract and calculated using the formula: [(Ao- $\left.\left.\mathrm{A}_{1}\right) / \mathrm{Ao}\right] * 100$; Ao is the absorbance of the blank solution and $\mathrm{A}_{1}$ is the absorbance of the positive control.

\subsection{Statistical Analysis}

The results are expressed as mean \pm standard deviation. Analysis of variance (one-way ANOVA) was used to check the significant mean difference and was achieved using SPSS 20. The measures were done in triplicate $(n=3)$. The obtained results were considered significant at $\mathrm{P} \leq 0.05$.

\section{RESUlts}

\subsection{Isolation and Extraction}

On completion of the isolation and purification processes of the endophytic fungi from the plant part under study, 7 fungal isolates (Cp1-Cp7) were recovered. The percentage yield of the extracts (fermentation product) recovered was observed to vary from one fungus to another. $\mathrm{Cp} 2$ was observed to have produced the highest amount of secondary metabolites $(126.6 \mathrm{mg})$ small-scaled fermentation under static conditions, while Cp7 produced the least amount (70.1 mg) (Table 1).

Table1. Yield of extracts of the isolated endophytic fungi

\begin{tabular}{|l|l|}
\hline Fungal extract & Yield (mg) \\
\hline Cp1 & 71.1 \\
\hline Cp2 & 126.6 \\
\hline Cp3 & 78.2 \\
\hline Cp4 & 84.4 \\
\hline Cp5 & 98.9 \\
\hline Cp6 & 124.9 \\
\hline Cp7 & 70.1 \\
\hline
\end{tabular}

Cp: Carica papaya

\subsection{HPLC Analysis}

Detection of the bioactive compounds produced by the fungi isolates in this work was achieved using HPLC analysis. The detected compounds are presented in Figure 2 and Table2. These compounds have been reported by several authors to exhibit varying biological activities.

Include the HPLC chromatogram here 

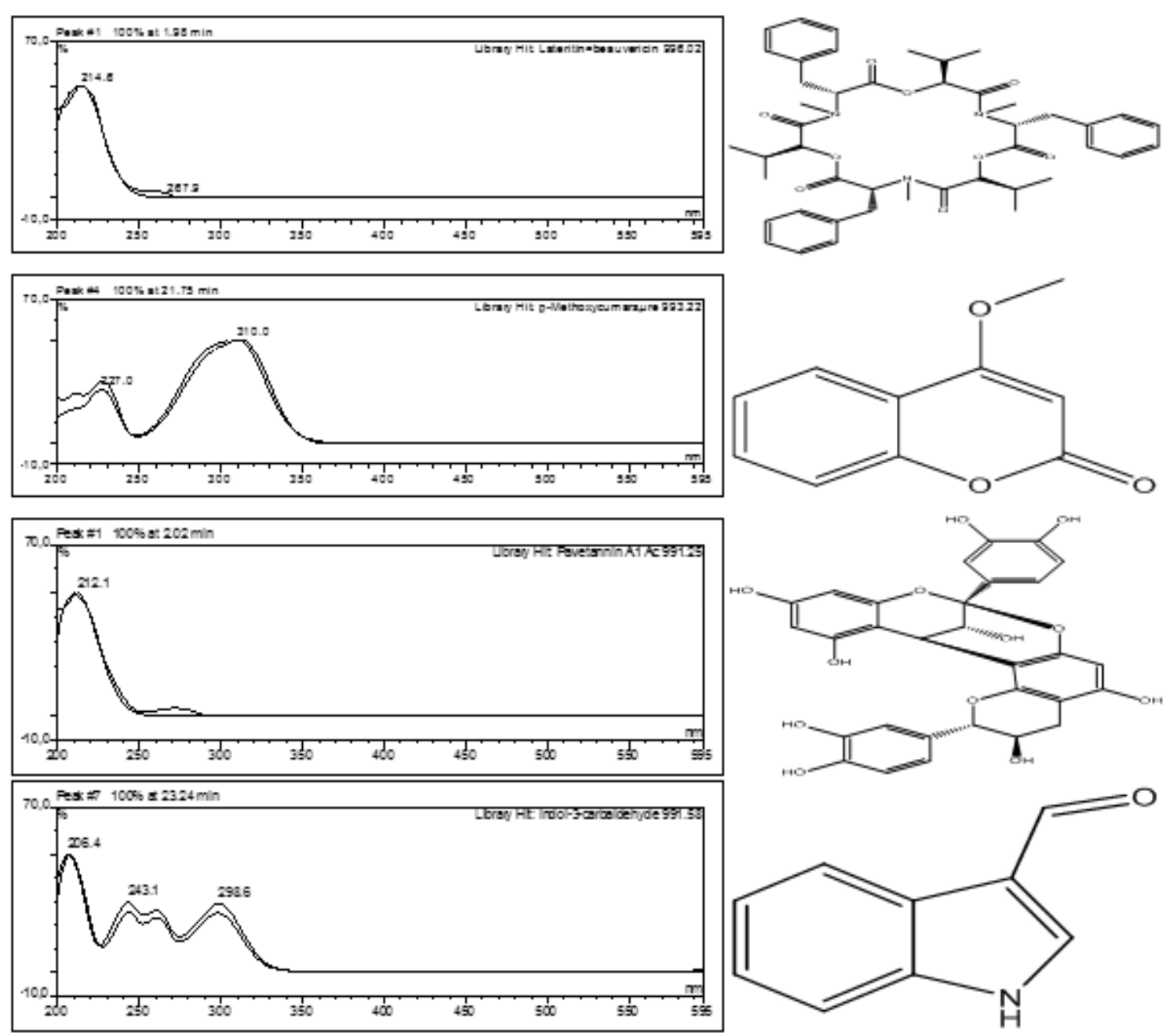

Figure2. HPLC chromatogram of the detected compounds showing beauvericin, p-methoxycoumarin, pavetannin $A 2$ and Indole carboxaldehyde; their $\boldsymbol{U V}$ spectra; and structures

Table2. The wavelength for maximum absorbance $\kappa_{\max }$ and retention time of the phytochemical compounds detected by HPLC-DADS for all the fractions of methanol extract

\begin{tabular}{|l|l|l|l|l|l|l|}
\hline Compound & $\begin{array}{l}\text { Class of } \\
\text { phytochemical }\end{array}$ & $\begin{array}{l}\text { Molecular } \\
\text { Formulae }\end{array}$ & $\begin{array}{l}\text { Molecular } \\
\text { Weight }\end{array}$ & $\begin{array}{l}\text { Rt } \\
(\mathbf{m i n})\end{array}$ & $\begin{array}{l}\boldsymbol{\Lambda}_{\text {max }} \\
(\mathbf{n m})\end{array}$ & $\begin{array}{l}\text { Biological } \\
\text { activity }\end{array}$ \\
\hline Beauvericin & Depsipeptide & $\mathrm{C}_{45} \mathrm{H}_{57} \mathrm{~N}_{3} \mathrm{O}_{9}$ & $783.96 \mathrm{~g} / \mathrm{mol}$ & 1.98 & $\begin{array}{l}214.6, \\
267.9\end{array}$ & $\begin{array}{l}\text { Antibacterial, } \\
\text { (Xu et al., 2010; } \\
\text { Antimalaria, } \\
\text { antituberculosis, } \\
\text { cytotoxicity, } \\
\text { (Isaka } \\
\text { et } \\
\text { al. } ., \\
\text { anti- } \\
\text { hepatoma, (Wang } \\
\text { et al., 2014) }\end{array}$ \\
\hline$p$-methoxycoumarin & Terpene lactones & $\mathrm{C}_{10} \mathrm{H}_{8} \mathrm{O}_{3}$ & $176.17 \mathrm{~g} / \mathrm{mol}$ & 21.75 & $\begin{array}{l}227.0, \\
310.0\end{array}$ & $\begin{array}{l}\text { Antioxidant, anti- } \\
\text { inflammatory, } \\
\text { antimicrobial, } \\
\text { anticancer, } \\
\text { (Mohammad } \\
\text { Asif, 2015) }\end{array}$ \\
\hline $\begin{array}{l}\text { Pavetannin A2 } \\
\text { Indole }\end{array}$ & Flavonoids & $\mathrm{C}_{30} \mathrm{H}_{24} \mathrm{O}_{12}$ & $576.51 \mathrm{~g} / \mathrm{mol}$ & 2.02 & 212.1 & $\begin{array}{l}\text { Antioxidant, } \\
\text { (Ramasamy } \\
\text { al., 2013) }\end{array}$ \\
\hline
\end{tabular}




\subsection{DPPH Scavenging Activity}

The ability of an extract to scavenge free radicals (DPPH) has been widely adopted in measuring the antioxidant potentials of plant and microbial extracts as well as chemically synthesized samples. This is attributed to its stable nature (Nabil, et al., 2014; Adél, et al., 2019).

The antioxidant activities demonstrated by the fungal extracts in this study was observed to be concentration dependent (CP1: $54.7 \pm 3.2,46.7 \pm 1.5,40.7 \pm 2.1,29.0 \pm 5.6$, and $22.0 \pm 2.0$; CP5: $51.3 \pm 3.5,33.7 \pm 5.5,27.3 \pm 1.5,23.7 \pm 2.9$, and $14.7 \pm 2.9)$ at $100,80,60,40,20 \mu \mathrm{g} / \mathrm{mL}$ respectively. Figures 3 (a-g). Although the activities demonstrated by these extracts can be said to be comparable to one another, but moderate when compared with the activity (AA: $75.0 \pm 2.6 ; 69.0 \pm$ $1.0,67.0 \pm 1.0,62.0 \pm 2.0$, and $57.0 \pm 0.0$ ) of the standard ascorbic acid at 100, 80, 60, 40, $20 \mu \mathrm{g} / \mathrm{mL}$. The DPPH radical scavenging activity of the fungal extracts was calculated and presented in Figures 3(a-g).
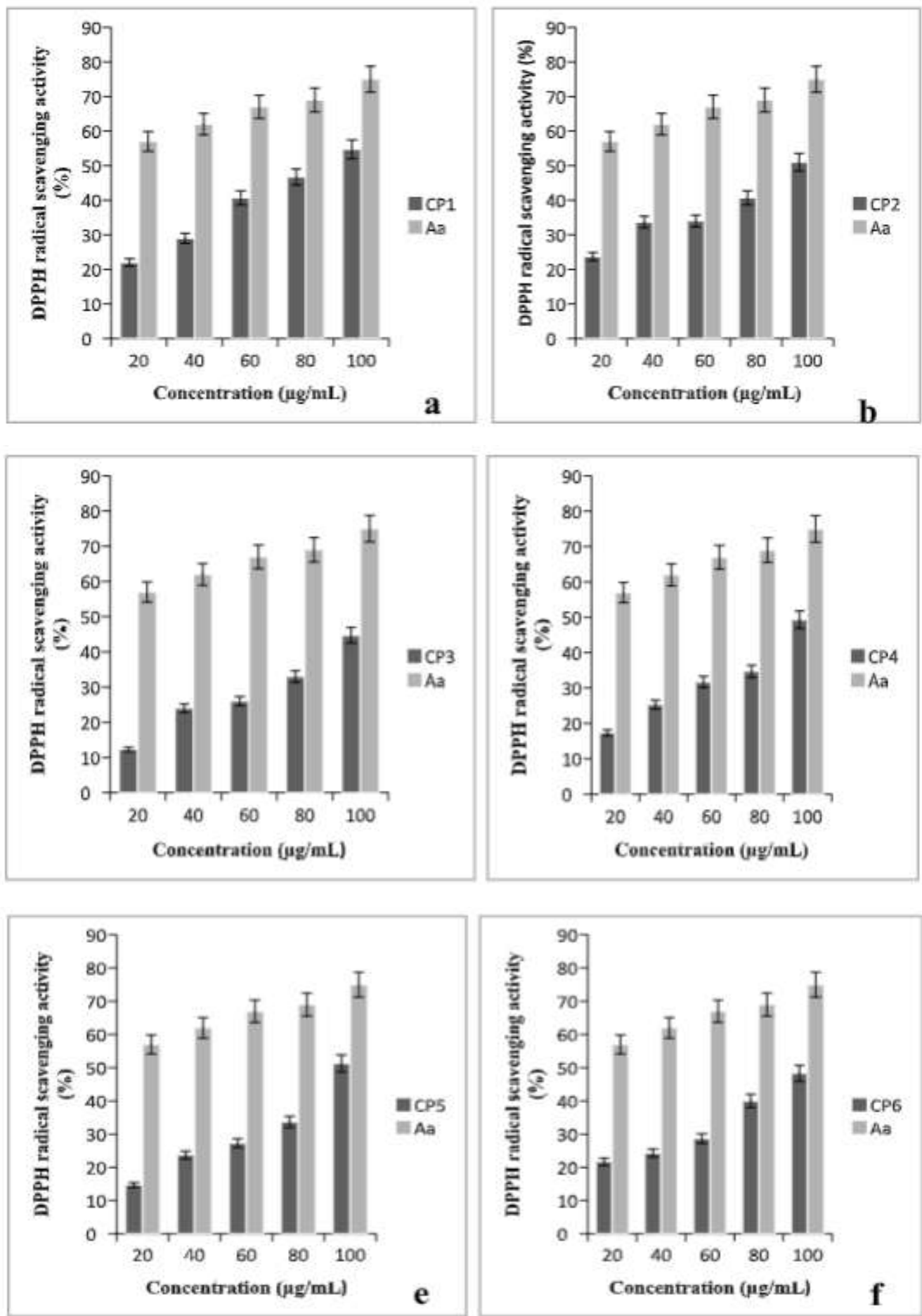


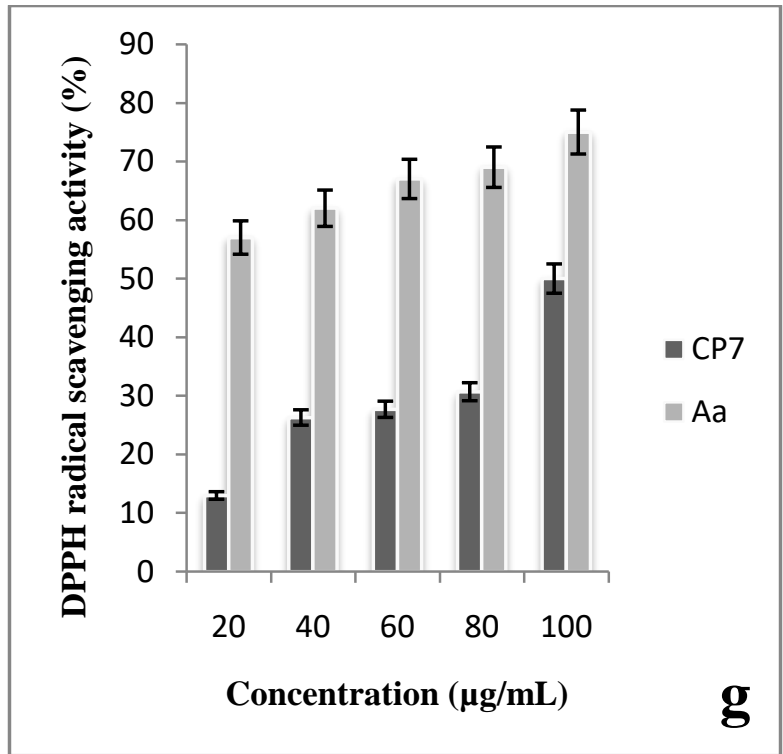

Figure3 (a-g). Result of the Percentage inhibition (\%) Produced by the endophytic fungi extracts and the standard Ascorbic acid, $(n=3)$ at $p<0.05$.

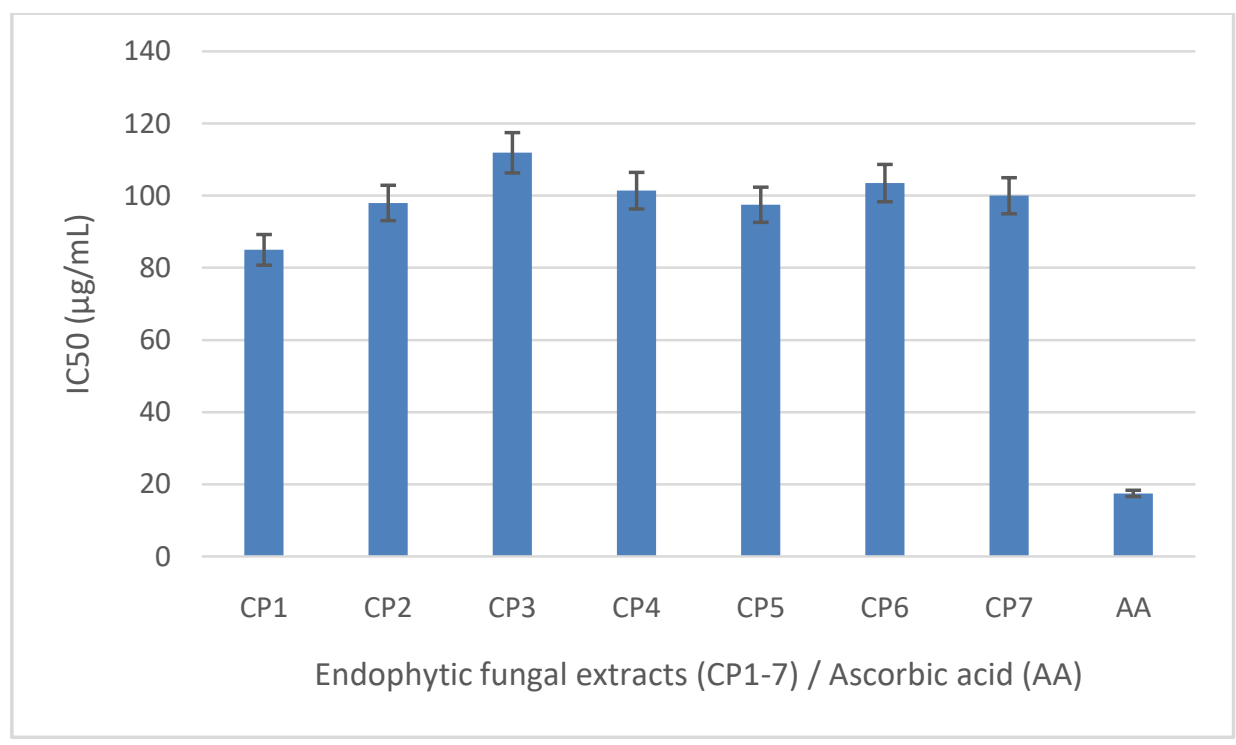

Figure4. Results of IC50

\section{DISCUSSION}

The free radical scavenging activity (RSA) of the endophytic fungal extracts at different concentrations $(20,40,60,80$ and $100 \mu \mathrm{g} / \mathrm{mL})$ was carried out in the presence of a freshly prepared solution of stable free radical DPPH $(0.1 \mathrm{~mol} / \mathrm{L})$ and compared with ascorbic acid as standard. DPPH is a free radical, stable at room temperature, which produces a violet solution in ethanol. It is reduced by receiving a hydrogen atom from antioxidants to the corresponding hydrazine; this gives rise to the deep violet colour (Mensor et al., 2001). We evaluated the scavenging effects of the endophytic fungal crude extracts on the DPPH radical. The activities of the fungal extracts were compared with that of the standard ascorbic acid. The results suggested that $\mathrm{Cp} 1, \mathrm{Cp} 5, \mathrm{Cp} 2$ and $\mathrm{Cp} 7$ fungal extracts exhibited moderate radical scavenging activities at $100 \mu \mathrm{g} / \mathrm{mL}$, demonstrating an inhibition that was observed to be concentration dependent Figure $3(\mathrm{a}-\mathrm{g})$. At a maximum concentration of $100 \mu \mathrm{g} / \mathrm{mL}$, fungal extracts $\mathrm{Cp} 1, \mathrm{Cp} 5, \mathrm{Cp} 2$ and $\mathrm{Cp} 7$ exhibited higher radical scavenging activities $54.7 \pm 3.2 \%$, $51.3 \pm 3.5 \%, 51.0 \pm 2.0 \%$, and $50.0 \pm 3.6 \%, \mathrm{IC}_{50} 85 \pm 1.5,97.5 \pm 3.5,98 \pm 2.0$ and $100 \pm 3.6$ respectively, [figure-3(a-g); figure-4], than other fungal extracts. These were the most effective fungal extracts whose antioxidant activities were observed to be moderate when compared to that of the standard ascorbic acid $75.0 \pm 2.6 \%$. However, Cp3 and $\mathrm{Cp} 4$ did not inhibit radical scavenging capacity. The radical scavenging activities by the active fungal extracts may be due to the presence of bioactive compounds as detected by HPLC analysis. 
The HPLC analysis of the fungal extract revealed the presence of important bioactive compounds with various biological activities including antimicrobial, cytotoxic, antiapoptotic, antimalarial, antihepatoma, (Xu et al., 2010; Isako et al., 2011; Wang et al., 2014). Therefore, the antioxidant activities demonstrated by the endophytic fungal extracts of $C$. papaya may be attributed to the combined effects of these bioactive compounds belonging to various classes (polyketides, phenols, alkaloids, terpenes, isoprenoids) detected in the extracts such as beauvericin, p-methoxycoumarin,

pavetannin A2 and indol-3-carboxaldehyde detected in $\mathrm{Cp} 1, \mathrm{Cp} 2, \mathrm{Cp} 5$ and $\mathrm{Cp} 7$ respectively. A comparison of the radical scavenging activities exhibited by the active fungal extracts and ascorbic acid in part is because the crude extracts may contain other classes of compounds that may be causing the antagonistic effect. However, isolation and testing of these bioactive compounds may show better activities. In this work, phenolic compounds (such as beauvericin, p-methoxycoumarin, pavetannin A2 and indol-3-carboxaldehyde) were detected in the active fungal extracts. Phenolic compounds are known for their good antioxidant capacities and also radical scavenging potentials is linked to both their phenolic rings and hydroxyl groups that combine to exhibit the antioxidative effect, and this is in accordance with previous studies Bahri-Sahloul et al., (2009); Djeridane et al., (2006), who demonstrated a significant correlation between phenolic composition and antioxidant activity. Djeridane et al., (2006) demonstrated also that coefficient correlation is respectively equal to 0.79 and 0.78 between antioxidant activity and total phenolic and flavonoids composition of Algerian plant extracts. Iwalokun et al., (2006) attributed the antioxidant activity to the presence of phenolic acids. Jung et al., (2002) reported that 4-hydroxyphenylacetic acid possesses radical scavenging abilities.

Indol-3-carboxaldehyde an indole alkaloid detected in $\mathrm{Cp} 7$ fungal extract indicates that the antioxidant potential demonstrated by the extracts may be due to the presence of both indole alkaloid and phenolic compound present in the extracts. These phytochemicals have been established to have very good antioxidant potentials (Adrianna et al., 2009; Ebenezer et al., 2011; Romasi et al., 2011). Although no report on the antioxidant activities of beauvericin and indol-3-carboxaldehyde exist rather antimicrobial activities nevertheless, several authors associated antimicrobial activity with the antioxidant potential.

Finally, this study showed that the antioxidant activity of the extracts of the endophytic fungi isolated fromC. papaya leaves was higher at the highest concentration $(100 \mu \mathrm{g} / \mathrm{mL})$ with Cp1demonstrating the highest antioxidant activity, but lower than the standard ascorbic acid and thus cannot be compared favorably with the standard antioxidant ascorbic acid. Thus further isolation and purification using advanced chromatographic separation techniques of the fungal crude extract may yield pure lead compounds that can be used in the development of antioxidant drugs.

\section{CONCLUSION}

Going by the vast amount of data available on bio-prospecting microorganism especially endophytic fungi for newer antioxidant agents, this work further validates the fact that these arereliable source of bioactive (lead compounds) molecules with greater intrinsic chemodiversity capable of being expressed by a single strain of an organism with a good prospect for discovery and development of newer effective drugs. Also, this is the first report on the detection ofbeauvericin biosynthesized by an endophytic fungus isolated from C. papaya leaves.These results could justify the use of these plants in traditional pharmacopoeia practice, thus further investigation on bioactive antioxidant compounds of endophytic fungi is important.

\section{ACKNOWLEDGMENTS}

We sincerely appreciate Institut für Pharmazeutische Biologie und Biotechnologie, Heinrinch-HeineUniversität, Düsseldorf, Gernany were the HPLC analysis was carried out.

\section{REFERENCES}

[1] Adél Szerlauth, Szabolcs Muráth, Sándor Viski, Istvan Szilagyi (2019). Radical scavenging activity of plant extracts from improved processing. Heliyon; Volume 5, Issue 11

[2] Adriana, B., Sergio, S., Vivienne, S., Maurizio, B., Antonella, M., Nicoletta, F., \& Sergio, R., (2009). Antimicrobial and antioxidant Activities of coumarins from the roots of ferulagocampestris (Apiaceaae). Molecules, 14,939-952 
[3] Ajaegbu EE, Danga YSP, Uzochukwu IC, Okoye FBC. Mosquito adulticidal activity of the leaf extracts of Spondias mombin L. against Aedes aegypti L. and isolation of active principles. J Vector Borne Dis. 2016;53:17-22.

[4] Ajaegbu, E. E., Ezugworie, F. N., Dieke, A. J., Ezeh, U. C., Ikuesan, A. J., Onuora, A. L., Nduka, F. O., Izekor, E. S., Tunde, A. A., Bassey, N. U., \& Ewa-Elechi, J. N. (2020). Antimicrobial Evaluation of the Extract/Fractions of the Millettia aboensis (Leguminosae) Stem against Streptococcus mutans. European Journal of Medicinal Plants, 31(13), 1-11.

[5] Alabi, O.A., Haruna, M.T., Anokwuru, C.P., Jegede, T., Abia, H., Okegbe, V. \& Esan, E. (2012). Comparative studies on antimicrobial properties of extracts of fresh and dried leaves of Carica papaya (L) on clinical bacterial and fungal isolates. Pelagia Research Library, 3(5): 3107-3114

[6] Aravind. G., Debjit, B., Duraivel, S., \& Harish, G. (2013). Traditional and Medicinal Uses of Carica papaya. Journal of Medicinal Plants Studies. 1(1):7-15

[7] Bahri-Sahloul, R.., Ammar, S., \& Fredj, S. R. (2009). "Polyphenol contents and antioxidant activities of extracts from flowers of two Crataegus azarolus L. varieties," Pakistan Journal of Biological Sciences, vol. 12, no. 9, pp. 660-668.

[8] Brand-Williams, M. E. Cuvelier, \& C. Berset. (1995). "Use of free radical method to evaluate antioxidant activity," Lebensmittel Wissenschaft und Technologie, Vol 28, Issue 1, 25-30

[9] Canini, A., Daniela, A., D’Arcangelo, G. \& Tagliatesta, P. (2007). Natural Products .Journal of Food Composition and Analysis.20(7): 584-590

[10] Cannon, P.F. (2002). Diversity and host preference of leaf endophytc fungi in Iwokrama forest ` Reserve, Guyana. Mycologia.Vol 94:2210-220

[11] Chan, L-K. \& Teo C-KH. (2002). Micropropagation of Eksotika, a Malaysia papaya cultivar, and the field performance of the tissue culture derived clones. Acta Horticulturae 575, 99-105

[12] Chigozie V, Okezie M, Ajaegbu E, Okoye F \& Esimone C. (2020). Isolation, identification, and evaluation of biological activities of Daldinia eschscholtzii, an endophytic fungus isolated from the leaves of Musa paradisiaca. GSC Biological and Pharmaceutical Sciences, 12(1), 216-228.

[13] Djeridane, A., M. Yousfi, B., Nadjemi, D., Boutassouna, P. Stocker, \& N. Vidal. (2006). “Antioxidant activity of some algerian medicinal plants extracts containing phenolic compounds," Food Chemistry, vol. 97, no. 4, pp. 654-660.

[14] Ebenezer, O. \& Faronbi O. (2011).Antioxidant and Chemopreventive properties of Vernonia amygdalina and Garcinia biflavonoid. Int. J. Environ. Res. Public Health. (8):2533-2555.

[15] Festus B.C. Okoye, Chukwuemeka S. Nworu, Abdessamad Debbab, Charles O. Esimone, Peter Proksch. (2015). Two new cytochalasins from an endophytic fungus, KL-1.1 isolated from Psidium guajava leaves Phytochemistry Letters 14 (2015) 51-55

[16] Festus Basden C. Okoye, Chukwuemeka S. Nworu, Peter A. Akah, Charles O. Esimone, Abdessamad Debbab, and Peter Proksch. (2013). Inhibition of inflammatory mediators and reactive oxygen and nitrogen species by some depsidones and diaryl ether derivatives isolated from Corynespora cassiicola, an endophytic fungus of Gongronema latifolium leaves. Immunopharmacol Immunotoxicol; 35(6): 640-646

[17] Filip, P., Weber, F.P., Sterner, R.W.S \& Ake, T. (2005). Hormonemate, a new cytotoxic and apoptosisinducing compound from the endophytic fungus, Hormonema dematoides 1. Identification of the producing strain, isolation and biological properties of hormonemate. Zeitschrift fur Natur for schung.58c: 547-552

[18] Igor Otavio Minatel, Cristine Vanz Borges, Maria Izabela Ferreira, Hector Alonzo Gomez Gomez, ChungYen Oliver Chen and Giuseppina Pace Pereira Lima (2017). Phenolic Compounds: Functional Properties, Impact of Processing and Bioavailability. DOI: 10.5772/66368

[19] Isaka, M.; Yangchum, A.; Sappan, M.; Suvannakad, R.; Srikitikulchai, P. (2011). Cyclohexadepsipeptides from Acremonium sp. BCC 28424. Tetrahedron; 67, 7929-7935. [CrossRef]

[20] Iwalokun, B.A, Efedede, B.U., Alabi-Sofunde J.A, Oduala T, Magbagbeola O.A. \& Akinwande A.I. (2006). Hepatoprotective and antioxidant activities of Vernonia amygdalina on acetaminophen-induced hepatic damage in mice. J. Med. Food.2006: 9:524-530. [PubMed]

[21] John W. Blun, Anthon R. Carroll, Brent R. Copp, Rohan A. Davis, Robert A. Keyzers and Michele R. Prinsep (2018). Marine natural products. Natural Products Reports, 35, 8-53.

[22] Ugochukwu M. Okezie, Peter M. Eze, Daniel L. Ajaghaku, Festus B.C. Okoye, Charles O. Esimone (2015). Isolation and screening of secondary metabolites from endophytic fungi Vernonia amygdalina and Carica papaya for their cytotoxic activity. Planta Medica; 81-PM_177 
[23] Jung YS, Kang TS, Yoon JH, Joe BY, Lim HJ, Seong CM, Park WK, Kong JY, Cho J, Park NS (2002) Synthesis and evaluation of 4-hydroxyphenylacetic acid amides and 4-hydroxycinnamamides as antioxidants. Bioorg Med Chem Lett 12:2599-2602

[24] Kalyana Sundram and Samir Samman (2006). Phenolic compounds in plants and agri-industrial byproducts: Antioxidant activity, occurrence, and potential uses. Food Chemistry, 99(1):191-203

[25] Marja P. Ka“hko“nen, Anu I. Hopia, Heikki J. Vuorela, Jussi-Pekka Rauha, Kalevi Pihlaja,

[26] Tytti S. Kujala and Marina Heinonen (1999). Antioxidant Activity of Plant Extracts Containing Phenolic CompoundsJ. Agric. Food Chem.47, 3954-3962

[27] Mensor L.L, Menezes F.S, Leitão G.G, Reis A.S, Dos Santos T.C, Coube C.S, \& Leitão S.G. (2001). Screening of brasilian plant extratcs for antioxidant activity by the use of DPPH free radical method. Phytother Res 15: 127- 130.

[28] Mohammad Asif. (2015). Overview of Diverse Pharmacological Activities of Substituted Coumarins: Compounds with Therapeutic Potentials. American Journal of Current Organic Chemistry. Voll, NO 1.

[29] Morton J.F. (1987). Papaya. In: Morton JF (Ed) Fruits of Warm Climates, Creative Resource Systems, Inc., Miami, FL, pp Diego, Calif., USA.pp. 336-45

[30] Nabil Qaid M Al-Hajj, Hong Xing Wang, Chaoyang Ma, Zaixiang Lou, Mohanad Bashari and Riyadh Thabit (2014). Antimicrobial and Antioxidant Activities of the Essential Oils of Some Aromatic Medicinal Plants (Pulicaria inuloides-Asteraceae and Ocimum forskolei-Lamiaceae). Tropical Journal of Pharmaceutical Research August; 13 (8): 1287-1293 ISSN: 1596-5996 (print); 1596-9827 (electronic).

[31] Nilanonta,C.;Isaka,M.;Kittakoop,P.;Palittapongarnpim,P.;Kamchonwongpaisan,S.;Pittayakhajon wut,D.; Tanticharoen, M.; Thebtaranonth, Y. (2000). Antimycobacterial and antiplasmodial cyclodepsipeptides from the insectpathogenic fungus Paecilomyces tenuipes BCC 1614. PlantaMed. ,66,756-758. [CrossRef][PubMed]

[32] Okezie U.M, Eze P.M, Okoye F.B.C, Ikegbunam M.N, Ugwu M.C, Esimone C.O (2017). Biologicall active Metabolites of an Endophytic Fungus isolated from Vernonia amygdalina. Vol.9 N0. 1; pp. 24-26

[33] Ramasamy Subramaman, Palanivel Subbramaniyan \& Vairamutha Raj (2013). Antioxidant activity of Stem bark of Shorea roxburghii and its silver reducing power. Springerplus

[34] Romasi, E F., Karina J. \& Parhusip, A J N. (2011).Antibacterial activity of papaya leaf extracts against pathogenic bacteria. Makara, Teknologi.15(2): 173-177

[35] Sari, Yustine Chung, Felicia Agatha and Hyung Kwoun Kim (2009). Evaluation of antioxidant and antimicrobial activity of phenolic lipids produced by the transesterification of 4-hydroxyphenylacetic acid and triglyceridesMustika. Appl Biol Chem (2019) 62:5 https://doi.org/10.1186/s13765-019-0419-3

[36] Xiaohan Wang, Xiao Gong, Peng Li, Daowan Lai and Ligang Zhou (2018). Structural Diversity and Biological Activities of Cyclic Depsipeptides from Fungi. Molecules;23(1), 169; https://doi.org/10.3390/molecules23010169

[37] Xican Li, Xiaozhen Wang, Dongfeng Chen, Shuzhi Chen (2011). Antioxidant Activity and Mechanism of Protocatechuic Acid in vitro. Functional Foods in Health and Disease 2011; 7:232-244 Page 232 of 244 Research Open Access

[38] Xu, L.; Wang, J.; Zhao, J.; Li, P.; Shan, T.; Wang, J.; Li, X.; Zhou, L. Beauvericin from the endophytic fungus, Fusarium redolens, isolated from Dioscorea zingiberensis and its antibacterial activity. Nat. Prod. Commun. 2010, 5, 811-814. [CrossRef] [PubMed]

[39] Vinton, M.A., Kathol, E.S., Vogel, K.P. \& Hopkins, A.A. (2001). Endophytic fungi in Canada wild rye in natural grasslands. J. Range Manage.54; In press.

[40] Wang, J.; Zhang, D.-M.; Jia, J.-F.; Peng, Q.-L.; Tian, H.-Y.; Wang, L.; Ye, W.-C. Cyclodepsipeptides from the ascocarps and insect-body portions of fungus Cordyceps cicadae. Fitoterapia 2014, 97, $23-27$. [CrossRef] [PubMed]

Citation: U.M. Okezie, et al., "Antioxidant Activities of Extracts of Endophytic Fungi Isolated from Healthy Leaves of Carica Papaya. International Journal of Research Studies in Biosciences”. 2020; 8(8): 48-56. DOI:https://doi.org/10.20431/2349-0365.0808005.

Copyright: (C) 2020 Authors. This is an open-access article distributed under the terms of the Creative Commons Attribution License, which permits unrestricted use, distribution, and reproduction in any medium, provided the original author and source are credited. 